\title{
19 A Sociological View on Hierarchical Failure: The Effect of Organizational Rules on Exchange Performance in Buyer- Supplier Transactions
}

\begin{abstract}
The classic Transaction Cost Economics view is that a key reason for firms to exist is that they offer a way to overcome problematic market transactions. If it is too complicated, expensive, or risky to buy a good on the market, consider hiring employees to make it in-house - especially if it is a good that you (and others) might need often. The implicit argument is that, for this reason, firms are a potentially rational response to less advantageous markets. However, firms are rational responses only when they themselves are organized in a way that is efficient enough to outperform the market. We consider firms' hierarchical efficiency by analyzing the existence and consequences of rules and procedures, effectively testing two competing arguments. On the one hand, rules and procedures are one way in which firms can achieve efficiency, through specialization and formalization of what a firm has learned. On the other hand, rules can be imprecise and rigid, a nuisance to deal with, and just coincidental traces of what has gone wrong in the past.

Using a database of more than 800 transactions in which German small and medium sized businesses buy ICT products and services, we consider the role of rules and procedures in a large-scale quantitative way. It turns out that rules show a pyramid-like structure where some firms have less and others have more codified rules. Our results furthermore suggest that rules might not be the clotted efficiency they have been argued to be. A high rule-density goes with increased investments in contracting ("thicker contracts") and not with decreased ex post transaction problems, questioning the benefits of rules as a way to favor firms over markets.
\end{abstract}

\subsection{Introduction}

Research into the management of inter firm exchange has, both theoretically and empirically, been dominated by transaction cost theory. The fundamental question addressed by transaction cost theory is why business firms exist (Williamson 1985; Coase 1937). Transaction cost theory proposes that in some cases markets fail to organize transactions efficiently, for instance when contractual hazards associated with transactions are too high. In such cases, instead of relying on the market to exchange

Gerrit Rooks, Chris Snijders, Eindhoven University of Technology

Frits Tazelaar, Utrecht University

○ Open Access. (C 2020 Gerrit Rooks, et al., published by De Gruyter. (c) BY-NC-ND This work is licensed under a Creative Commons Attribution-NonCommercial-NoDerivatives 4.0 International License.

https://doi.org/10.1515/9783110647495-019 
goods and services, a hierarchy of contractual employee relations is the more effective and efficient option (in-house production). This "make-or-buy" decision is at the heart of the transaction cost theory paradigm, and extensions of this principle, that relate to the extent to which a firm should invest in managing the products or services that they decide to buy, have found their way into economics, sociology, and neighboring disciplines (cf. Batenburg et al. 2003; Raub et al. 2007; Rooks et al. 2000; Rooks et al. 2006; Buskens and Raub 2013; Wynstra et al. 2018). While transaction cost theory's predictions have received some empirical support, many questions remain (cf. Rindfleisch and Heide 1997; David and Han 2004; Geyskens, Steenkamp, and Kumar 2006). One fundamental unexplored area is the structure and content of the hierarchy itself. A hierarchy can be defined as a governance mode that "by means of an authority structure, provides one exchange partner with the ability to develop rules, give instructions, and in effect impose decisions on the others.” (Geyskens, Steenkamp, and Kumar 2006: 525).

Under which conditions firms develop rules, and how exchange performance is affected by these rules, are questions that have received comparatively little attention. They are important questions though, since more insight in the costs and benefits of the use of rules will allow researchers to better assess when hierarchies outperform other governance modes such as markets and hybrid governance forms that include relational elements (March et al., 2000). Although formal organizational rules have since long been an important ingredient in theories about bureaucratization of organizations and societies as a whole (Gouldner 1954; Weber 1947), we know surprisingly little about their effects in general (Beck and Kieser, 2003), and their effects on contractual planning in particular. Williamson has stressed on several occasions (Swedberg 1990; Williamson 1996), that the strengths and weaknesses of hierarchy need to be better understood. In his words, economists "are greatly in need of a more adequate theory of bureaucracy", thereby urging sociologists "to call these issues to our attention, lay out their significance, and impress upon us to be responsive" (Swedberg 1990: 124). He also stressed that "in comparison with the study of market failure, the study of hierarchical failure is seriously underdeveloped. If, however, each generic mode of governance enjoys distinctive strengths and weaknesses, then that disparity should be redressed. Chief among the issues that warrant study in this connection is that of bureaucracy" (Williamson 1996: 17).

The aim of our study is to extend the literature and empirically investigate what the effects of organizational rules are. We explicate and test how (formal) organizational rules - in our case internal organizational rules on procurement - affect the contractual planning of a purchasing transaction. The contractual planning of a transaction is a complex set of activities that comprises negotiating and writing contracts, as well as enforcing contracts. Additionally, we test whether rules affect exchange performance, which we define operationally as the number of problems that occur in the ex post phase of a transaction, and a more subjective measure, namely the satisfaction of the buyer with the product and supplier. We make use of a comprehensive data set containing detailed information about 832 purchasing transactions in Germany. 


\subsection{Theory and hypotheses}

Organizational rules provide procedures for problem solving (Beck and Kieser 2003). We are interested in rules that specify which actions have to be taken by employees or departments given a certain type of transaction. More specifically, we focus on the set of rules developed to deal with issues in the area of procurement and consider how the 'density' of internal organizational procurement rules affects ex ante management of a purchase transaction. Following Schulz (1998: 849) we define rule density as "the number of rules in a given organizational rule population at a given time”. Essentially, rule density thus refers to the number of specified rules in a given problem area (as a percentage of the total number of possible rules). In our case the population of rules consists of all potential internal procurement rules. Although it is not obvious that existing rules will necessarily be followed (cf. Borry et al. 2018), we do not consider this issue and assume that, by and large, organizational rules are followed (or at least that the more rules there are, the more rules are followed).

\subsubsection{Rules as rational adaptations or irrational coincidences}

One of the earliest and most prominent scholars to focus on organizational rules was Max Weber, who explained that the economic advantages of specialization through a division of work can only be realized on the basis of formal rules. Rules and rulefollowing are an essential element of bureaucracy, which, according to Weber, is a superior form of organization. Formalization increases standardization, precision, and the speed of organizational processes. Formal rules also restrict the organizational members' room for egoistic maneuvers and arbitrary decisions. Moreover, formal rules control and coordinate organizational processes and increase their predictability (Weber 1947). In Weber's view, organizational rules are efficient. One of the reasons for this is that organizational rules store knowledge (Beck and Kieser 2003; Hage 1965; Schulz 1998). Collective experience is transferred to individual and new members through rules 'that reflect but do not reproduce the experiences on which they are based' (March, as cited in Beck and Kieser 2003). The idea that rules are efficient is shared by rational action theories that explain the existence of rules as an efficient way to coordinate action, "a conception of historical efficiency underlies many speculations about rules" (March et al. 2000: 4). Rules are expected to represent what an organization has learned about dealing with matters, both within the organization itself and in relation to other organizations (Williamson 1996).

A more or less opposing view proposes that organizational rules may be inefficient as well. Although it is acknowledged that rules can achieve coordination, in this view rules are often rigid and imprecise means to achieve coordination of activities as well. Blau (1957: 68) expressed this view as follows “... effective administration is 
contingent on uniform adherence to regulations as well as on adaptability to a variety of specific situations, but bureaucratic pressures compelling strict conformity to rules also give rise to rigidities that interfere with the adaptability needed to handle special cases".

Schultz (1998) distinguished two mechanisms that inhibit or eliminate the effectiveness of rules as organizational learning devices: 'codification traps' and 'sorting'. Codification traps can occur when old rules are applied to new problems: a new situation or problem does not really match a rule, but is used nevertheless. The rule is often 'stretched' or extended to apply better to the problem. Such codification traps are inhibiting organizational learning and lead to inefficiencies because old, inadequate rules might be needlessly reinforced, and the perceived need to create new better rules is decreased. Another inefficiency can be the result of what Schulz calls 'sorting'. Sorting is shorthand for the phenomenon that the most recurring and important problems are encoded into solutions and rules first, while less recurrent and less important problems are encountered and encoded later, or they are not encoded in rules at all. Because of this temporal sequence, rules that are created in response to recurrent problems are likely to be based on relatively old and obsolete knowledge, leading to inefficiencies.

Over time, the discussion on organizational rules has led to literature on closely related concepts such as organizational formalization (the extent to which rules, procedures, instructions, and communications are written), organizational routines (informal rules that came about in an informal way), 'red tape' (rules and routines that do not make sense any more), organizational learning and ecology, and many other, related but subtly different concepts. Whereas theoretical papers about the concepts are plentiful, field studies on organizational rules are relatively rare and often based on archival research (cf. Bozemann and Feeney 2014; Kaufmann and van Witteloostuijn 2018).

\subsubsection{Rules and ex ante management}

Although there are contradicting ideas about the relationship between organizational rules and contracting, there has been remarkably little large-scale empirical research on effects of rules (Bozemann and Feeney 2014). Above we discussed two arguments that point to the potential inefficiency of organizational rules. In this section we discuss the effects of organizational rules of the buyer on the ex-ante management of a transaction. We focus on the buyer, since this is the empirical focus of the paper. We distinguish two dimension of ex ante management: the content and the effort involved. The content of ex ante management in our case refers to the extensiveness of the contract between buyer and supplier. Second, we discuss effects of organizational rules on the effort involved in the ex-ante management, more specifically, we focus on the cost of contracting, which is measured as the number of full-time equivalent 
days spent negotiating and drafting the initial contract. We hypothesize that organizational rules are not necessarily efficient. Organizational rules often lead to more safeguards and higher ex ante transaction costs, than would be necessary on the basis of the relevant characteristics of a transaction by itself.

The first reason is that rules are often founded as a response to crises and serious problems with the aim to prevent that same problem in the future (Zhou 1993), "the stable door is locked after the horse has bolted". Rules are then created to prevent certain problems to reoccur. In situations that resemble the previously problematic situation, preventive measures will now have to be taken because the rules prescribe those preventive actions. Since new situations might well be qualitatively substantially different from the previous problematic situations, the application of the rule is often unnecessary (Schulz 1998). So, rules are applied to prevent problems, and are calibrated (if at all) in such a way that they will be executed also in cases where they would not have been necessary, which obviously leads to higher transaction costs compared to the cases where no or less rules are at play. Rules tend to give descriptions of what to do extra, not what to do less. The latter point also suggests the second argument: as rules typically require additional things to do, there are higher costs involved in terms of time and effort when there are more rules that have to be applied (Ouchi 1979). Furthermore, evidence also suggests that rules are not regularly refreshed or revoked: "[the increase in the number of rules] reflects the creation of many new rules [. . .] without the repeal of rules" (Jakobsen and Mortensen 2016: 302). ${ }^{1}$

Hypothesis 1: The larger the rule-density in a buyer's organization is, the more extensive the contract between the buyer and the supplier will be.

Hypothesis 2:The larger the rule-density in a buyer's organization is, the higher the cost of contracting associated with a transaction will be.

\subsubsection{Rules and exchange performance: The tradeoff between flexibility and efficiency}

In the classical Weberian view, formalization is thought to increase standardization, precision, and the speed of organizational processes. Formal rules also restrict the organizational members' room for egoistic maneuvers and arbitrary decisions, and control and coordinate organizational processes and increase their predictability (Weber 1947). In Weber's view, organizational rules are associated with better

1 A recent paper has also shown that because of the rigor of most rules, employees commonly mention rules as one of the key constraints that they experience in their work (Pindek et al. 2019). Contradicting arguments in the area of organization routines (not rules) can be found in for instance Feldman and Pentland (2003), who argue that routines do not necessarily create inertia and rigor. 
performance, and fewer errors. One reason is that organizational rules store knowledge. Formalization codifies best-practice routines to stabilize and diffuse new organizational capabilities (Nelson and Winter 1982). Collective experience is transferred to individual and new members through rules 'that reflect but do not reproduce the experiences on which they are based' (March, as cited in Beck and Kiesler 2003). So, rules are associated with bureaucratic forms of organizations with high levels of standardization, specialization, and ultimately, efficiency.

Formal rules have a downside as well. Too much organizational structure implies that organizations become rigid and inflexible (Sine, Mitsuhashi, and Kirsch 2006). Highly standardized routines make organizations resistant to change (Hannan and Freeman 1984). Rules lock organizations into inflexible patterns of action (Gersick and Hackman 1990). So, according to the literature, structure can have an up and downside. Rules can lead to efficiency and reliability, but also to rigidity and inertia. In line with earlier research, we consider whether there is a tradeoff between efficiency and flexibility (Adler, Goldoftas, and Levine 1999). Too little structure does not guide the required behavior enough, and does not facilitate coordination enough, but too much structure leads to a lack of flexibility and overly cautious interactions. This argument is consistent with the findings in the simulation study by Davis, Eisenhard, and Bingham (2009): organizations with a low or high amount of rules perform worse than those with moderate structure. This leads to the following hypothesis.

Hypothesis 3: Rule density has an inverted U-shaped relationship with exchange performance.

\subsubsection{Rule density, environmental dynamism, and exchange performance}

There is a long-standing literature that argues that effects of organizational structure on performance depend on the dynamism of the environment of that organization, and the extent to which the rules and routines can keep up with changing circumstances. Contingency theory is the most prominent theory that studies this relation (Galbraith 1973; Schoonhoven 1981). It maintains that there is no one best way of organizing. The effectiveness of a certain organizational form will depend on the degree of task uncertainty. Organizations should adopt a more efficient mechanistic form if the task is simple and stable, while it should adopt a more flexible organic form if the task is complex and changing (Burns and Stalker 1961). A basic assumption that the theory makes is that under conditions of greater uncertainty, more information must be processed to achieve a certain level of performance (Galbraith 1973: 4). As a consequence, organizations are less able to plan ahead or to make decisions under conditions of greater uncertainty, and consequently performance will be worse under such conditions.

In dynamic environments transactions will be more often non-routine tasks. Whereas rules help to efficiently deal with routine purchasing tasks, they are not well 
suited for the non-routine purchasing tasks. One way to deal with non-routine tasks is to apply 'old' rules to new circumstances: a new situation or problem does not really match a rule, but is used nevertheless. If rules are applied in completely inappropriate situations, then the contract performance will deteriorate (Schoonhoven 1981). This argument is similar to the "codification traps" idea of Schulz (1998), which also discusses the dangers of applying old rules to new problems. The rule is often stretched or extended to apply better to the problem. Such codification traps lead to inefficiencies, and inhibit organizational learning because old, inadequate rules are reinforced, and the perceived need to create new and better rules is reduced.

A second possible inefficiency because of environmental dynamism can be the result of 'sorting' (Schultz 1998). Sorting refers to the phenomenon that the most recurring problems are encoded into solutions and rules first, while less recurrent problems are encoded later, if at all. Sorting is thus related to the decay of routines and rules as described by Hannan and Freeman (1984). Organizations remember by doing (Nelson and Winter 1982), and hence organizational rules and routines that are not used often, decay. Because of this temporal sequence in sorting, rules that are created in response to recurrent problems are likely to be based on relatively old obsolete knowledge, leading to inefficiencies. Sorting is related to 'routine rigidity', which is a failure to change organizational processes. Routine rigidity may result from the fact that some routines are very tightly aligned with one certain environment, since they are so adapted to this one environment, they are difficult to change because effective and self-reinforcing, and not built to adapt to discontinuities (Gilbert 2005).

Although the argument that environmental dynamism influences the relation between organizational rules and performance is plausible and supported by some empirical results, it has been criticized as being imprecise, since environmental dynamism is a multi-dimensional construct (Davis et al. 2009; Dess and Beard 1984). In their simulation study into the relation between organizational rules and performance Davis et al. (2009) distinguish four dimensions: unpredictability, ambiguity, complexity, and velocity. Velocity and unpredictability refer to global characteristics of opportunities and threats in the environment that are less relevant at the transactional level. Since we focus on the environment of the exchange, and not the organization as a whole, we focus here on performance ambiguity and task complexity. Performance ambiguity refers to a lack of clarity in the exchange because the buyer lacks experience or knowledge to evaluate the partner's performance; task complexity refers to the number of sub-task and the interrelatedness between those sub-tasks.

Hypothesis 3a: The relationship between rule-density and exchange performance is moderated by performance ambiguity. Rules work better when there is less ambiguity.

Hypothesis 3b: The relationship between rule-density and exchange performance is moderated by task complexity. Rules work better when there is less task complexity. 


\subsubsection{Control Variables: Organizational Capabilities and Transaction Characteristics}

More recently, scholars have also recognized that organizational capabilities influence governance decisions (Argyris 1996; Leiblein and Miller 2003; Mayer and Salomon 2006; Mayer 2006; Nickerson and Silverman 2003). Designing a contract has been claimed to be a firm capability that influences contractual planning and, exchange performance in interorganizational relationships. Contract design capabilities reside in the rule within a firm, but also in managers, engineers, and lawyers (Argyris and Mayer 2007). In this paper we control for possible confounding effects of organizational capabilities by including in our models the existence of separate departments with specialized tasks (a legal department, a purchase department, an IT-department, and/or a finance department). These specialized departments form an indication for both governance capabilities and technical capabilities of the firm. Given these capabilities, it seems likely that the ex-ante governance of transactions can take place with higher expertise and lower transaction costs. Although these arguments make it sound as if we assume that the existence of a specialized department is necessarily efficient, many of the considerations about inefficiencies mentioned above with respect to the use of organizational rules may hold for organizational capabilities as well. For example, suppose that the rule is that for large or frequent transactions the legal department should (always) be involved, even if the other contractual hazards (e.g. asset specificity, uncertainty, complexity and/or a lack of competition in the market) are quite low. In such a case, the use of the internal legal specialists is likely to be overkill. However, as with rules, having specialized departments is likely to increase contract density, even without assuming optimal efficient use of the department capabilities.

Other control variables are based on transaction cost theory. Transaction cost theory had its starting point with the seminal article of Coase (1937) 'The Nature of the Firm'. Later, Williamson operationalized the theory by defining particular transaction characteristics that determine governance choices. The most prominent set of transaction characteristics are specific investments (e.g., Williamson 1985). If transactions require investments that cannot be redeployed to alternative uses without loss of productive value, then contractual hazards due to dependency arise. Transaction partners can profit opportunistically from this dependency, given that circumstances permit this.

The second transaction characteristic that plays a prominent role in the theory is uncertainty, which relates to the inability to predict changes in the environment and partners' behavior. Uncertainty is assumed to vary, meanwhile being always present to at least some extent. Due to uncertainty, combined with bounded rationality, contracting is always costly, and complete contracting not feasible.

A third transaction characteristic that is identified in the theory, although it has received less attention in empirical TCE research (David and Han 2004) is the frequency of transactions. Frequency is relevant in two respects: reputation effects and 
setup costs (Williamson, 2008: 8). According to Williamson (Williamson 1985: 60) higher levels of transaction frequency provide an incentive for a firm to employ hierarchical governance because "the cost of specialized governance structures will be easier to recover for large transactions of a recurring kind".

Transaction cost theory maintains that there are rational economic reasons for choosing the means of governing transactions. If market transactions become too costly, transactions will be vertically integrated: the firm will choose to arrange matters in-house. In the transaction cost view, an organization exists because it can manage transactions with contractual hazards at lower costs than the market can. Empirically, transaction costs theory has received a fair amount of support, though not always that consistently (Rindfleisch and Heide 1997; David and Han 2004; Geyskens, Steenkamp, and Kumar 2006).

Following Milgrom and Roberts (1992) two other characteristics of the transaction are taken into account as well, namely task complexity and (lack of) competition. Task complexity precipitates transaction costs by introducing ambiguity about the cause of transaction failure, which in turn makes it difficult to apportion blame between the transacting partners. Moreover, complexity creates a need for coordination among transaction partners. A lack of competition in the supplier's product market may increase the buyer's dependency, and therefore the intensity of competition can be seen as a force that reduces transaction hazards.

\subsection{Methods}

To test the hypotheses, we make use of a database resulting from a comprehensive survey of IT-purchases by German small and medium sized business (Berger, Kropp, and Voss 2000). This multi-purpose survey was part of a wider Dutch-German cooperative project; the survey was based on an earlier pilot study (Tazelaar, Vaessen, Blumberg, and Raub 1995), as well as on earlier large-scale surveys that were conducted in a related research project in the Netherlands (Batenburg 1997).

The questionnaire contained six major parts, concerning (a) the product and/or service, (b) product and supplier selection, (c) the relationship between the buyer and the supplier, (d) the agreement and contracting, (e) the performance of the supplier, problems, and problem management, and (f) the buyer and his or her relation to the supplier. In total, per transaction more than 300 items were scored. In the survey buyers of information technology in two regions, Halle/Leipzig and Munich, in (then East and West) Germany were sampled. At the time of the survey both regions (Halle/Leipzig and Munich) were economically prosperous regions.

In order for a transaction from a given firm to be included in the survey, the firm had to meet the following requirements: 1) it should be a small or medium sized firm with 4 to 500 employees; 2) it had managed the purchase itself, the decisions about 
the product and supplier had been taken by the firm instead of a mother company; 2) an employee of the firm was willing and able to give detailed information about the transaction; 3) the transaction was completed not too long ago - if possible not longer than three years; 4) the transaction should involve only one supplier. To compile the sampling frame the yellow pages were used ('Gelben Seiten für Deutschland. Frühjahr 1999').

The data collection was conducted in two stages. First, a member of the research team contacted the firm in the sample by phone to determine whether the firm met the requirements to be part of the survey, and if this was the case, whether the firm was willing to cooperate in the survey. If a firm agreed to cooperate with the survey, and met the requirements, then a knowledgeable contact person who had been responsible for purchases of information technology was selected and an appointment was made for a face-to-face interview (if firms refused a face-to-face interview a questionnaire was mailed to them).

The telephone interviews started in March 1999 and were concluded in August 1999 (Berger, Kropp and Voss 2002). All firms that agreed to cooperate were sent a letter of confirmation immediately after the telephonic interview. In this letter the selected transaction and the date and time of the appointment were named again. Shortly before the agreed face-to-face interview a member of the research team phoned the firm once more to confirm the appointment. If possible, the respondent was asked after the interview whether he or she was willing to fill out a second (written) questionnaire.

As a result of the high care intensity and the personal assistance in filling out the questionnaires, the response rates to the face-to-face interview were high. The survey team realized $84.2 \%$ of all the promised interviews. Additionally, $24.5 \%$ of the respondents filled out a second questionnaire. The response to the mail questionnaire was substantially lower (36.4\%). The overall response rate was $49 \%$, which is high compared to the standard response rates in organization research (see Kalleberg et al. 1996). The response rate in the region of Halle/Leipzig was higher than in the region of Munich: 57\% versus 44\% (Rooks, Tazelaar, and Snijders 2010).

The data set that was collected contains detailed information about 1,019 ITtransactions from 832 buying firms. From these 832 buying firms, 645 (=78\%) provided data on a single IT-transaction and $187(=22 \%)$ provided data on a second IT-transaction as well.

\subsection{Measurements}

As mentioned before in the data section, the survey was based on a number of earlier large-scale surveys that were conducted in a related research projects in the Netherlands. Many of the measurement items used in this article were tested and calibrated in earlier studies using other data-sets (Rooks and Snijders 2001; Batenburg 
et al. 2003; Rooks et al. 2006). Besides our main variables of interest: rule density, firm specialization, contract extensiveness, and ex post performance, we control for several TCE-characteristics and other contextual characteristics.

\subsubsection{Organizational characteristics}

\subsubsection{Rule density}

To measure rule density, we constructed an instrument that consisted of six items that covered procurement rules. More specifically, the six items were about the management of six essential purchasing tasks, such as the search and selection of suppliers. The items were tested in two small scale survey studies. Every item involved a certain broader problem area, such as which departments or which functions are to be involved in the search, screening, and selection of suppliers. Respondents could indicate whether there were written rules (documents) that covered the problem area. The items and descriptive statistics are shown in Table 19.1.

Table 19.1: Rules and regulations, ordered from most used to least used.

Nr of obervations Proportion that has rule Mokken's H item score

1 Type of agreement / contract that has to be used (an order / standard contract / tailor made contract)

2 Tendering / collecting and judging tenders or offers

3 Departments and/or capabilities that are to be involved in search,

screening and selection of buyers

4 Departments and/or capabilities that are to be involved in negotiating, designing and concluding contacts

5 Departments and / or capabilities that are to be involved in conflict 
Table 19.1 (continued)

\begin{tabular}{lccr}
\hline & Nr of obervations & Proportion that has rule & Mokken's H item score \\
\hline 6 & 841 & 0.13 & 0.70 \\
$\begin{array}{l}\text { Evaluating suppliers } \\
\text { performance }\end{array}$ & 841 & 0.13 & 0.70 \\
$7 \begin{array}{l}\text { Benchmarking / periodical } \\
\text { supplier evaluations }\end{array}$ & 844 & 0.10 & 0.59 \\
$8 \begin{array}{l}\text { Supplier audits and } \\
\text { product presentations by } \\
\text { suppliers }\end{array}$ & & & \\
\hline
\end{tabular}

Rules are often codified in a temporal order. First, the most severe and recurrent problems are codified, whereas less recurrent problems will be codified later (Schulz 1998). To investigate patterns in organizational rules and the scalability of our items we performed a nonparametric item response analysis, the so-called Mokken model (Mokken 1971). This model can be viewed as a probabilistic version of Guttman scale analysis for dichotomous items. An advantage of this nonparametric model compared to parametric versions of item response models such as the well-known Rasch model is that it is more flexible, and sometimes avoids misleading results obtained by parametric models (Junker and Sijtsma 2001; Meijer and Baneke 2004). We used the MSP5 program (Molenaar and Sijtsma 2000) to estimate the model. The results are shown in Table 19.1. According to (Mokken 1971: 185) for practical test construction purposes $H$ values lower than .3 are not scalable, $.3 \leq H \leq .4$ denote a weak scale, $.4 \leq$ $H \leq .5$ denote a medium scale, while $H$-values above .5 denote a strong scale.

According to the criteria, the items form a very strong scale (Mokken's Hcoefficient $=0.68$ ). The reliability of the scale is comparable to Cronbach's alpha and in our case is adequate (Rho $=.82$ ). The sum of all eight the items form the variable rule density. The finding that the items constitute a Mokken scale is interesting. Apparently, there is an order in the kinds of rules that a firm uses. There obviously exist more frequently used rules, such as rules with respect to the type of agreement that is supposed to be used, and less frequent ones, such as rules about supplier audits. The key finding is that there is a hierarchy in this set of rules, where firms typically tend to implement rules in a bottom-to-top step-by-step way: firms differ in the extent to which they are formalized not only by the number of rules they have, but they differ in how far up the rules-pyramid they are.

\subsubsection{Organizational capabilities}

We measure organizational capabilities using information that the survey respondents provided about the departments in the organization. Purchasing is a dummy variable indicating whether or not there was a purchase department present in the firm $(18 \%$ of 
the SMEs had a purchasing department). Automation is a dummy variable indicating whether or not there was a automation department (17\% of the SMEs had an automation department). Legal is a dummy variable indicating whether or not there was a legal department (only 4\% of the SMEs had a legal department). Finance is a dummy variable indicating whether or not a financial department was present in the firm $(21 \%$ of the SMEs had a financial department).

\subsubsection{Firm size}

According to Nooteboom, Zwart, and Bijmolt (1992) smaller firms are (more) bounded in their rationality. It is more difficult for smaller firms compared to larger firms to monitor suppliers' performance for instance. In other words, Nooteboom et al. (1992: 144) argue that transaction costs are systematically higher for smaller firms. "Costs of governance schemes to reduce transaction costs are often relatively higher for small firms: transactions may be too small to be worth the bother of such a scheme.”. The arguments about firm size related to well-known argument about differentiation and firm size (Blau 1970). We use the number of employees of the buyer at the time of the transaction as an indicator for firm size. The variable firm size is the logarithm of the number of employees, with 30 cases (2.94\%) imputed using information about sales volume. Likewise, the firm size of the supplier, size partner, is the logarithm of the number of employees of the supplier at the time of the transaction; 17 cases $(1.67 \%)$ were imputed using information about the type of supplier.

\subsubsection{Transaction characteristics}

\subsubsection{Asset specificity}

Asset specificity reflects the possible exposure to ex post opportunistic holdup caused by specific investments in physical and/or human assets that have little or no value outside of the transaction. We measure asset specificity using four survey questions about switching costs. Switching costs are the expected costs should the supplier be replaced with another supplier. The first question relates to the tendering costs, the costs of searching, screening and selecting a new supplier for a new product. The second question involves the loss in terms of time and money associated (re)training and instruction of personnel. The third question relates to the costs of (renewed) data entry. The fourth question is about the loss in terms of time and money associated with idle production. Together, these four items form a reliable scale (Cronbach's alpha $=0.82$ ). 


\subsubsection{Uncertainty}

We measure uncertainty using two survey questions as indicators. The first question relates to the difficulty of assessing a supplier's quality at the time of delivery. The second question is in an historical reference frame; respondents were asked to recall the period of time when the contract was initially signed. The question relates to difficulties in comparing offers between suppliers. The reliability coefficient of this 2-item scale (Cronbach's alpha $=0.73$ ).

\subsubsection{Transaction size}

Transaction frequency is a transaction characteristic that has received scant attention in transaction cost theory, this in sharp contrast to asset specificity and uncertainty. According to Williamson (1985: 60) higher levels of transaction frequency provide an incentive for firm to employ hierarchical governance because "the cost of specialized governance structures will be easier to recover for large transactions of a recurring kind.”. The nature of transactions that we study is such that transactions are unlikely to be repeated in substance for any pair of transaction partners. Nonetheless, large projects are more significant determinants of current and future profits of both partners, and hence governance will be more beneficial. We use as a single indicator for transaction size the approximate price (in German Marks). We imputed 46 cases $(4.51 \%)$ using information about the perceived importance and durability of the product or service. Since the distribution of this variable is highly skewed with many outliers a logarithmic transformation is applied.

\subsubsection{Task complexity}

Task complexity creates a need for coordination between transacting firms. Transactions that involve many different parts, software and hardware that interact in unpredictable way to produce services or products are more complex. We use a measure that was based on two indicators. The first indicator measures the scope of the products and services covered by the transaction. It is a count of the number of products and services covered by the transaction (the questionnaire contained a checklist of 18 components). A second indicator is a categorization of technological complexity developed by Anderson and Dekker (2005) that represents increasing demands for communication and coordination between the buyer and supplier. The correlation between the two indicators is high $(r=0.61)$. The two indicators form a reliable scale (Cronbach's alpha $=0.69$ ). 


\subsubsection{Competition}

Market forces are thought to reduce transaction hazards. Two questions are used to measure competition. The first question asks about the size of the pool of potential suppliers that were identified when the firm searched for suitable transaction partners. The second question asks for the number of different products, i.e. alternatives that could have met the buyer's needs at the time of purchase. The two question correlate highly $(\mathrm{r}=0.77)$ and constitute a reliable scale (Cronbach's alpha $=0.87$ ).

\subsubsection{Dependent variables}

\subsubsection{Contract extensiveness}

The questionnaire contained a list of 22 financial, legal, and operational issues that can be included in a written (ICT) contract. The respondents were asked to indicate which of the items were included in the written contract. Following Anderson and Dekker (2005), we measure contract extensiveness as the number of items included in the written contract.

\subsubsection{Cost of contracting}

We measure the cost of contracting as the number of full-time equivalent days spent negotiating and drafting the initial contract. A log-transformation is applied to the skewed raw variable (ranges from less than one day to 60). Although the measure has some limitations, for instance it only takes into account costs of contracting that are directly related to labor, it is an improvement over earlier measures (Anderson and Dekker 2005).

\subsubsection{Ex post transaction problems}

A separate section of the questionnaire contained questions about the ex post phase of the transaction. Questions were asked about 11 typical problematic issues that are often associated with IT-transactions (Riesewijk and Warmerdam 1988). Respondents could indicate for each issue to what extent it had occurred and how serious the problem had been. The eleven issues are measured on a five-point scale (ranging from 'not whatsoever' to 'very severe'). The variable ex post problems is derived as a scale score on these eleven issues (Cronbach's $\alpha=0.92$; higher represent more and/ or more serious problems). The average score was 14.7. For 282 transactions of the 878 in the sample (32\%) a modest or severe problem (3-4) occurred. Most correlations 
between the different types of problems are rather high (lowest $r=0.35$, highest $r=0.77$ ), hence problems often appear simultaneously.

\subsubsection{Exchange performance: Satisfaction buyer}

We asked the respondents to give two marks to indicate their satisfaction with the supplier and the product. The respondent could indicate on a scale from 1 ("very good") to 6 ("unsatisfactory"). A third indicator was a question whether the respondent would recommend the supplier "Would you and your employees recommend the supplier to other firms as a result of the delivery of this product, or would you not recommend supplier?" The answer scale ranged from 1 "definitely not recommend" to 5 "definitely recommend". Based on these three questions we constructed a variable Performance (Cronbach's $\alpha=0.83$; higher score represents better performance).

\subsection{Results}

We estimate our models using ordinary multiple regression analysis, using robust standard errors to account for potential heteroscedasticity, and the partially nested structure of the data (182 firms provided information about two transactions).

Looking at Table 19.2 from a distance, we note several interesting observations. First, transaction characteristics have a strong influence on both contracting characteristics and ex post problems. Higher asset specificity, higher uncertainty, higher complexity, and higher task complexity go with more extensive and more costly contracts. Moreover, contract extensiveness indeed decreases ex post problems (cutting away about half the effect of transaction size, for instance), but even after controlling for contract extensiveness, more complicated transactions (uncertain, large, and complex) are associated with more ex post problems. Another interesting finding is that the only characteristics that seem to matter for exchange performance are uncertainty and rule density (and their interaction).

Focusing on our hypotheses, we see that contracts get more extensive, the more written procedures there exist in the focal firm. This is in concordance with Hypothesis 1. Rules and procedures indeed tend to be associated with more extensive contracts. The data hence support the idea that rules and procedures are of the kind "make sure to perform A and B", and not of the kind "under such and such conditions, you need not worry about C and D". Holding constant transaction characteristics, the more written rules there exist in the focal firm, the higher the cost of contracting. This is in concordance with Hypothesis 2. That is, transactions with a higher 'problem potential' receive more transaction management. 


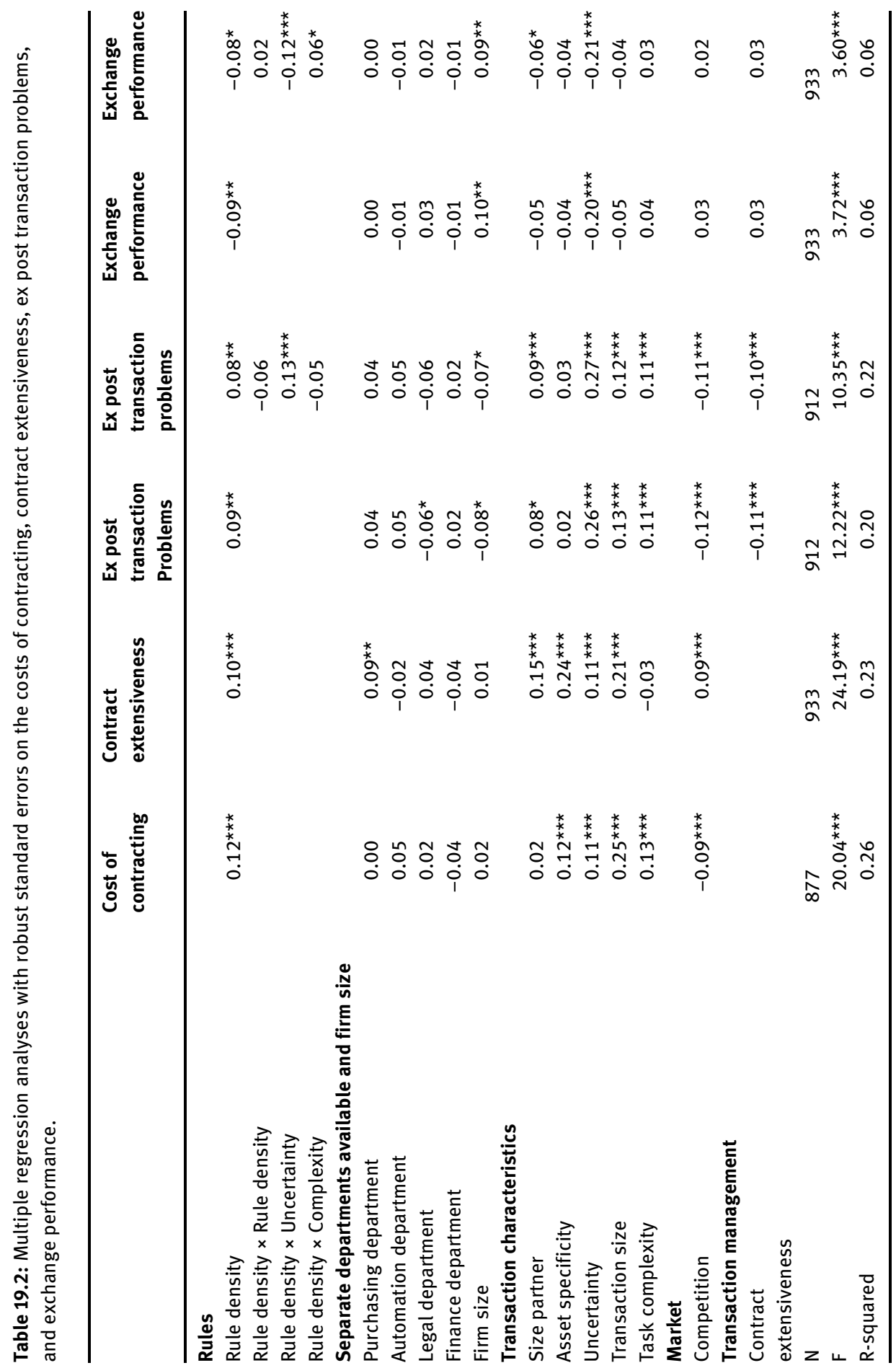


We do not find that there is an optimal number of rules that balances flexibility and efficiency. The quadratic effect of rules finds no support, and alternative ways to test for the inverse U-shape, such as breaking up the analysis in two separate parts (not reported here), also do not show any evidence to support Hypothesis 3. By and large, rules lead to more transaction management, but not to a decrease in problems or an increase in performance. Hypothesis 3 is therefore not supported. We do see that rules are even less effective when there is more performance ambiguity, which supports Hypothesis 3a, albeit in the sense that rules are less bad when there is low performance ambiguity. However, this effect is not found for more complex transactions. Hypothesis $3 \mathrm{~b}$ is not supported.

\subsection{Discussion and conclusion}

In this study we tested how formal organizational rules affect the contracting costs, contract extensiveness, and exchange performance, namely the number of problems that occur in the ex post phase of a transaction, and overall satisfaction of the buyer. The picture that emerges from our results is one of hierarchical failure. The more organizational rules, the more extensive contracts and contracting costs. The extra management effort that is taken because of existence of rules is not compensated for by better exchange performance, however. To the best of our knowledge this study is the first large scale study into effects of bureaucratization on transaction costs.

Our results have important theoretical implications. A main implication is that the costs of ex ante management and ex-post exchange performance are affected by the level of bureaucracy, especially when a firm is confronted with uncertainty. Bureaucratic costs have been recognized as a factor Williamson (1991: 279) "One advantage of hierarchy over the hybrid with respect to bilateral adaptation is that internal contracts can be more incomplete. [. . . The advantages of hierarchy over hybrid in adaptation $\mathrm{C}$ respects are not, however, realized without cost. Weaker incentive intensity (greater bureaucratic costs) attend the move from hybrid to hierarchy, ceteris paribus." Our results suggest that those bureaucratic costs should be taken into account when studying comparative economic organization. Including bureaucratic costs in the calculus of economic governance of governance, may explain why hybrid organizations are so common.

A second implication is that our findings may offer at least a partial answer to the question that was raised in the meta-analysis of Geyskens, Steenkamp and Kumar (2006). The effect of relational governance on exchange performance was found to be substantially larger than that of hierarchical governance. As an explanation the researchers point to the strength of relational governance, such as flexibility and superior information sharing, but ignore potential weaknesses of hierarchical governance forms. Our results suggest that when hierarchical governance is too 
bureaucratic (consists of mainly if-then rules), hierarchies will fail, and hybrid forms of governance are more likely to outperform bureaucratic governance structures.

It is an open question why and when the existence of rules and regulations lead to additional problems. One reason might be that they tend to add detrimental content to a contract. Or, perhaps the rules are such that they lead to other behavior that does not find its way in the contract, but nevertheless leads to more problems than one would expect without the rules. On the other hand, it seems that similar arguments cannot (or need not) be made about purchasing departments: when they are around the contracts get more extensive and that helps preventing problems. However, one might still wonder whether the benefits outweigh the costs in this case. Is a purchasing department worth the money? Our data cannot provide any definitive test on this issue as it needs (even) more detailed measurement.

A second issue that we left untouched is the fact that it might make quite a difference whether the contract itself was made by the buyer or the supplier. The argument for that dates back to at least Macaulay's "battle of the forms": the party who can write down the rules is usually better off. In fact, our data do allow a more thorough test of the importance of who the designer of the contract is, which we leave to a future paper.

A third issue that we did not consider in this study is the genesis of organizational purchasing rules. Under which conditions do firms develop rules? One possibility is suggested by transaction cost theory itself. Empirically, the transaction characteristics asset specificity and uncertainty have received the bulk of research attention. The transaction cost theoretical framework includes a third characteristic, "transaction frequency". Transaction frequency refers to the extent to which transactions recur (Williamson 1985). Williamson suggests that transaction frequency will affect hierarchical governance: "The cost of specialized [i.e., hierarchical] governance structures will be easier to recover for large transactions of a recurring kind. Hence the frequency of transactions is a relevant dimension. Where frequency is low but the needs for nuanced governance are great, the possibility of aggregating the demands of similar but independent transactions is suggested." (Williamson 1985: 60) Then again, one might wonder to what extent rules indeed are such rational adaptations, given that our results suggest that they might be less optimal than one would expect. Perhaps the explanation lies in humans' systematic irrational responses to rational demands instead.

\section{Bibliography}

Adler, Paul S., Barbara Goldoftas, and David I. Levine. "Flexibility versus Efficiency? A Case Study of Model Changeovers in the Toyota Production System.”; Organization Science 10, no. 1 (1999): 43-68.

Anderson, Shannon W., and Henri C. Dekker. “Management Control for Market Transactions: The Relation between Transaction Characteristics, Incomplete Contract Design, and Subsequent Performance." Management Science 51, no. 12 (2005): 1734-1752. 
Argyres, Nicholas. "Evidence on the Role of Firm Capabilities in Vertical Integration Decisions." Strategic Management Journal 17, no. 2 (1996): 129-150.

Argyres, Nicholas, and Kyle J. Mayer. "Contract Design Capabilities and Contract Performance by High Technology Firms: Implications for the Roles of Lawyers, Managers, and Engineers." In Proceedings of the 8th Annual ISNIE Conference, Tucson Arizona. 2004.

Argyres, Nicholas, and Kyle J. Mayer. "Contract design as a firm capability: An integration of learning and transaction cost perspectives." Academy of Management Review 32, no.4 (2007): 1060-1077.

Batenburg, Ronald S., and A. Van de Rijt. "The External Management of Automation 1995: Codebook of MAT95." ISCORE paper 58 (1997).

Batenburg, Ronald S., Werner Raub, and Chris Snijders. "Contacts and contracts: dyadic embeddedness and the contractual behavior of firms." Research in the Sociology of Organizations 20, no. 1 (2003): 135-188.

Beck, Nikolaus, and Alfred Kieser. "The Complexity of Rule Systems, Experience and Organizational Learning." Organization Studies 24, no. 5 (2003): 793-814.

Berger, Roger, Per Kropp, and Thomas Voss. "Das Management des EDV-Einkaufs 1999." Codebook. Leipzig: Arbeitsbericht des Instituts für Soziologie 14 (2000).

Blau, Peter M. "Formal Organization: Dimensions of Analysis." American Journal of Sociology 63, no. 1 (1957): 58-69.

Blau, Peter M. “A Formal Theory of Differentiation in Organizations.” American Sociological Review 35 (1970): 201-218.

Borry, Erin L., Leisha DeHart Davis, Wesley Kaufmann, Cullen C. Merritt, Zachary Mohr, and Lars Tummers. "Formalization and Consistency Heighten Organizational Rule Following: Experimental and Survey Evidence." Public Administration 96, no. 2 (2018): 368-385.

Bozeman, Barry, and Mary K. Feeney. Rules and Red Tape: A Prism for Public Administration Theory and Research: A Prism for Public Administration Theory and Research. Armonk, NY: M. E. Sharpe 2014.

Burns, Tom, and George M. Stalker. "The Management of Innovation. London.” Tavistock Publishing. Cited in Hurley, RF and Hult, GTM (1998). Innovation, Market Orientation, and Organisational Learning: An Integration and Empirical Examination. Journal of Marketing 62 (1961): 42-54.

Buskens, Vincent, and Werner Raub. "Rational Choice Research on Social Dilemmas: Embeddedness Effects on Trust." Handbook of Rational Choice Social Research (Stanford University Press, Redwood City, CA), Rafael Wittek, Tom A.B. Snijders, Victor Nee, eds. (2013): 113-150.

Coase, Ronald Harry. “The Nature of the Firm." Economica 4, no. 16 (1937): 386-405.

David, Robert J., and Shin-Kap Han. "A Systematic Assessment of the Empirical Support for Transaction Cost Economics." Strategic Management Journal 25, no. 1 (2004): 39-58.

Davis, Jason P., Kathleen M. Eisenhardt, and Christopher B. Bingham. "Optimal structure, Market Dynamism, and the Strategy of Simple Rules.” Administrative Science Quarterly 54, no. 3 (2009): 413-452.

Dess, Gregory G., and Donald W. Beard. "Dimensions of Organizational Task Environments." Administrative Science Quarterly 29 (1984): 52-73.

Feldman, Martha S., and Brian T. Pentland. "Reconceptualizing Organizational Routines as a Source of Flexibility and Change." Administrative Science Quarterly 48, no. 1 (2003): 94-118.

Galbraith, Jay. Designing Complex Organizations. Addison-Wesley Longman Publishing Co., Inc., (1973): 156-177.

Gersick, Connie JG, and J. Richard Hackman. "Habitual Routines in Task-Performing Groups.” Organizational Behavior and Human Decision Processes 47, no. 1 (1990): 65-97. 
Geyskens, Inge, Jan-Benedict EM Steenkamp, and Nirmalya Kumar. "Make, Buy, or Ally: A Transaction Cost Theory Meta-Analysis." Academy of Management Journal 49, no. 3 (2006): 519-543.

Gilbert, Clark G. "Unbundling the Structure of Inertia: Resource versus Routine Rigidity.” Academy of Management Journal 48, no. 5 (2005): 741-763.

Gouldner, Alvin W. Patterns of Industrial Bureaucracy. New York: The Free Press (1954).

Hage, Jerald. “An Axiomatic Theory of Organizations.” Administrative Science Quarterly 10 (1965): 289-320.

Hannan, Michael T., and John Freeman. "Structural Inertia and Organizational Change." American Sociological Review 49 (1984): 149-164.

Jakobsen, Mads LF, and Peter B. Mortensen. "Rules and the doctrine of performance Management." Public Administration Review 76, no. 2 (2016): 302-312.

Junker, Brian W., and Klaas Sijtsma. "Nonparametric Item Response Theory in Action: An Overview of the Special Issue.” Applied Psychological Measurement 25, no. 3 (2001): 211-220.

Kale, Prashant, Jeffrey H. Dyer, and Harbir Singh. "Alliance Capability, Stock market Response, and Long-Term Alliance Success: The Role of the Alliance Function." Strategic Management Journal 23, no. 8 (2002): 747-767.

Kalleberg, Arne L., et al., eds. Organizations in America: Analysing their structures and human resource practices. Sage, 1996.

Kaufmann, Wesley, and Arjen van Witteloostuijn. "Do Rules Breed Rules? Vertical Rule-Making Cascades at the Supranational, National, and Organizational Level." International Public Management Journal 21, no. 4 (2018): 650-676.

Leiblein, Michael J., and Douglas J. Miller. "An Empirical Examination of Transaction-and Firm-Level Influences on the Vertical Boundaries of the Firm." Strategic Management Journal 24, no. 9 (2003): 839-859.

March, James G., Martin Schulz, and Xueguang Zhou. The Dynamics of Rules: Change in Written Organizational Codes. Stanford University Press, 2000.

Mayer, Kyle J. "Spillovers and Governance: An Analysis of Knowledge and Reputational Spillovers in Information Technology." Academy of Management Journal 49, no. 1 (2006): 69-84.

Mayer, Kyle J., and Robert M. Salomon. "Capabilities, Contractual Hazards, and Governance: Integrating Resource-Based and Transaction Cost Perspectives." Academy of Management Journal 49, no. 5 (2006): 942-959.

Meijer, Rob R., and Joost J. Baneke. "Analyzing Psychopathology Items: a Case for Nonparametric Item Response Theory Modeling." Psychological methods 9, no. 3 (2004): 354.

Roberts, John, and Paul Milgrom. Economics, Organization and Management. Englewood Cliffs, NJ: Prentice-Hall, 1992.

Mokken, Robert Jan "A theory and procedure of scale analysis. The Hague, The Netherlands: Mouton 1971.

Mokken, Robert Jan. A Theory and Procedure of Scale Analysis: With Applications in Political Research. Vol. 1. Berlin, Germany: Walter de Gruyter, 2011.

Molenaar, Ivo W., and Klaas Sijtsma. “User’s Manual MSP5 for Windows.” Groningen: iecProGAMMA (2000).

Nelson, Richard R. An Evolutionary Theory of Economic Change. Harvard University Press, 2009.

Nelson, Richard R., and Sidney G. Winter. "An evolutionary theory of economic change." Cambridge, Mass. and London, Belknap Harvard, 1982.

Nickerson, Jack A., and Brian S. Silverman. "Why Firms Want to Organize Efficiently and What Keeps Them From Doing So: Inappropriate Governance, Performance, and Adaptation in a Deregulated Industry." Administrative Science Quarterly 48, no. 3 (2003): 433-465. 
Nooteboom, Bart, Peter Zwart, and Tammo Bijmolt. "Transaction Costs and Standardisation in Professional Services to Small Business.” Small Business Economics 4, no. 2 (1992): 141-151.

Ouchi, William G. "A Conceptual Framework for the Design of Organizational Control Mechanisms." Management Science 25, no. 9 (1979): 833-848.

Pindek, Shani, David J. Howard, Alexandra Krajcevska, and Paul E. Spector. "Organizational Constraints and Performance: an Indirect Effects Model." Journal of Managerial Psychology 34, no. 2 (2019): 79-95.

Raub, Werner, Gerrit Rooks, and Frits Tazelaar. "Erträge des Sozialkapitals in Zwischenbetrieblichen Beziehungen: Eine Empirisch-theoretische Studie." Sozialkapital: Grundlagen und Anwendungen. Sonderheft der KZfSS 47 (2007): 241-271.

Riesewijk, Bernard., and J. Warmerdam. Het Slagen en Falen van Automatiseringsprojecten [Translation: "Success and failure of IT-projects"]. (1988).

Rindfleisch, Aric, and Jan B. Heide. "Transaction Cost Analysis: Past, Ppresent, and Future Applications." Journal of Marketing 61, no. 4 (1997): 30-54.

Rooks, Gerrit, Werner Raub, Robert Selten, and Frits Tazelaar. "How Inter-Firm Co-operation Depends on Social Embeddedness: A Vignette Study." Acta Sociologica 43, no. 2 (2000): 123-137.

Rooks, Gerrit, Werner Raub, and Frits Tazelaar. "Ex Post Problems in Buyer-Supplier Transactions: Effects of Transaction Characteristics, Social Embeddedness, and Contractual Governance." Journal of Management \& Governance 10, no. 3 (2006): 239-276.

Rooks, Gerrit, and Chris Snijders. "The Purchase of Information Technology Products by Dutch SM Es: Problem Resolution.” Journal of Supply Chain Management 37, no. 3 (2001): 34-42.

Rooks, Gerrit, Frits Tazelaar, and Chris Snijders. "Gossip and Reputation in Business Networks." European Sociological Review 27, no. 1 (2010): 90-106.

Schoonhoven, Claudia Bird. "Problems with Contingency Theory: Testing Assumptions Hidden Within the Language of Contingency Theory”." Administrative Science Quarterly 26 (1981): 349-377.

Schulz, Martin. "Limits to Bureaucratic Growth: The Density Dependence of Organizational Rule Births.” Administrative Science Quarterly 43 (1998): 845-876.

Sine, Wesley D., Hitoshi Mitsuhashi, and David A. Kirsch. "Revisiting Burns and Stalker: Formal structure and new venture performance in emerging economic sectors." Academy of Management Journal 49, no.1 (2006): 121-132.

Swedberg, Richard. Economics and Sociology: Redefining their Boundaries: Conversations with Economists and Sociologists. Princeton University Press, 1990.

Tazelaar, F., P. M. M. Vaessen, B. F. Blumberg, and W. Raub. "Samenwerking tussen Inkoper en Leverancier: Verslag van een Vooronderzoek naar het Management van Inkooptransacties (ISCORE-paper No. 40)." Utrecht: Universiteit Utrecht (1995).

Weber, Max. The Theory of Social and Economic Organization. Simon and Schuster, 1947.

Williamson, Oliver E. The Economic Institutions of Capitalism. New York: The Free Press (1985).

Williamson, Oliver E. "Comparative economic organization: The analysis of discrete structural alternatives." Administrative Science Quarterly, 36 (1991): 269-296.

Williamson, Oliver E. The Mechanisms of Governance. Oxford University Press, 1996.

Williamson, Oliver E. "Outsourcing: Transaction Cost Economics and Supply Chain Management." Journal of Supply Chain Management 44, no. 2 (2008): 5-16.

Wynstra, Finn, Gerrit Rooks, and Chris Snijders. "How is Service Procurement Different from Goods Procurement? Exploring Ex Ante Costs and Ex Post Problems in IT Procurement." Journal of Purchasing and Supply Management 24, no. 2 (2018): 83-94.

Zhou, Xueguang. “The Dynamics of Organizational Rules.” American Journal of Sociology 98, no. 5 (1993): 1134-1166. 